\title{
ON SPERMATIC TRANSMISSION IN SPIDERS
}

\author{
By J. W. Abalos ${ }^{1}$ and E. C. Baez ${ }^{2}$
}

Lister observed in 1678 that in copulation the male spider applies its palpi to the genital opening of the female, and since then the mechanics of sperm transmission has provided a fascinating problem for research. Formerly it was thought that there existed an internal communication between the organs of spermatogenesis and the palpi; careful studies have shown a total lack of such a connection.

In 1843 , Menge described the construction by the mature male of a nuptial web into which (or directly into the web of the female) he deposits a drop of semen. The semen is produced in his abdominal reproductive organs, a pair of gonads with their respective deferent ducts meeting to form a terminal duct, opening at the midline of the body into a seminal vesicle in the epigastric furrow. This drop of semen is then taken up by the copulatory apparatus situated in the male palpi, which are transformed for this purpose into more or less complex organs, according to the spider family. Once the palpi are filled with sperm, the male is ready for mating.

Copulation is preceded by a courtship typical for each species and described by various authors. The male introduces the embolus of one palpus into the female epigynum, transferring the sperm into the seminal receptacle; immediately afterwards he repeats the operation with the other palpus. The deposition of the sperm in the nuptial web as described by Menge was later observed by various authors, among whom Montgomery ( 1903 ) suggested the term "sperm induction".

Various authors have tried to explain the origin of this double process (sperm induction and copulation). Alexander and Ewer (1957) summarize the literature and try to explain sperm induction, postulating a protoarachnid that, originally aquatic and later becoming terrestrial, was unable to return to the water and thus transformed fertilization to an internal process in agreement with its new habitat. Considering the reproductive process in those arachnid groups in which there is no direct contact of the respective genital openings (scorpions, pseudoscorpions, solpugids and some mites), the authors consider the different possibilities available to the protoarachnid, and arrive at the following conclusion: "From a comparative survey of the mating habits of those arachnids for which the facts are known,

\footnotetext{
${ }^{1}$ Instituto Nacional de Microbiología, Santiago del Estero, Argentina.

${ }^{2}$ Instituto de Animales Venenosus, Santiago del Estero, Argentina.

Manuscript received by the editor A pril 10, 1963.
} 


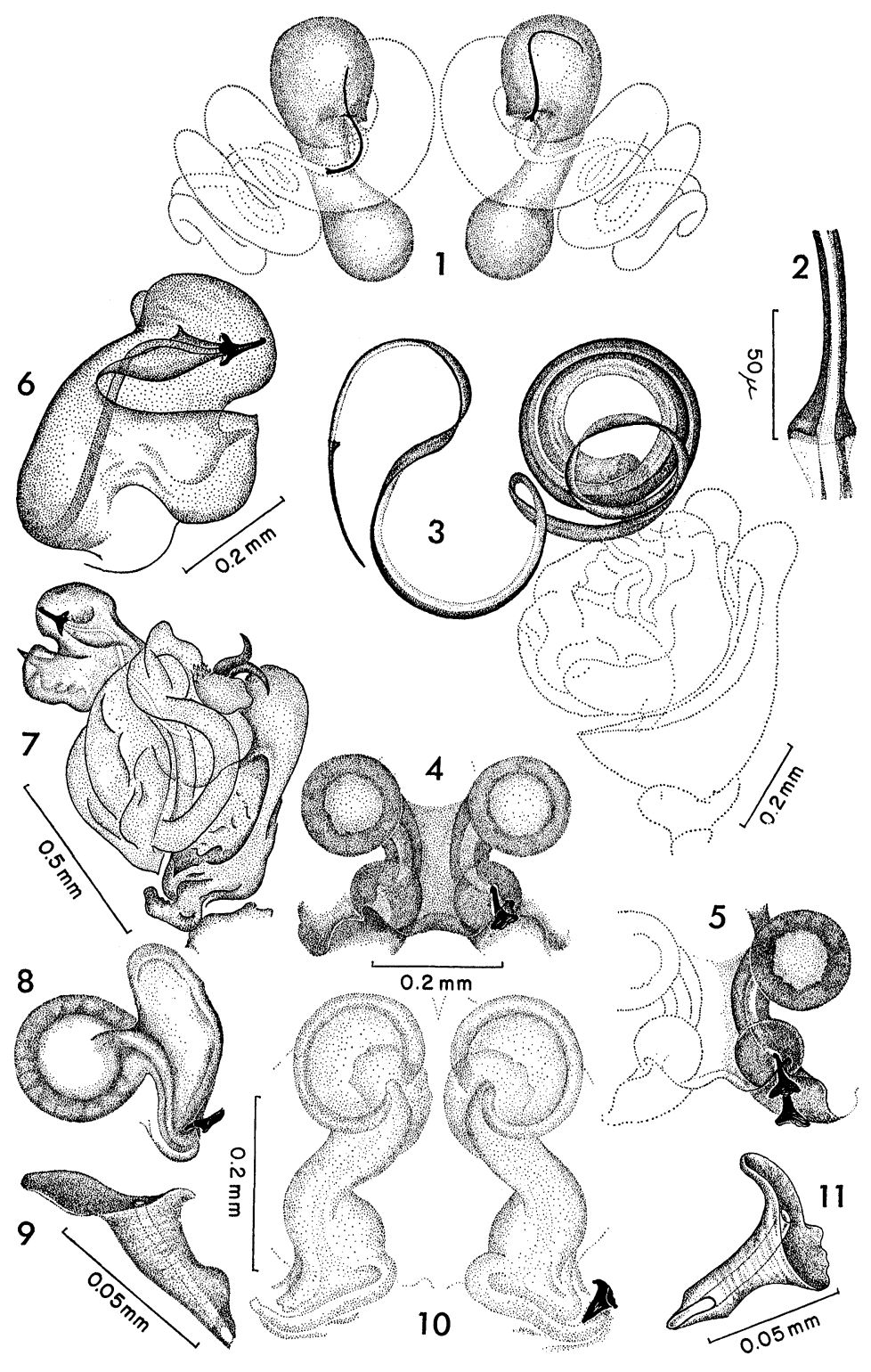

Abalos and Baez - Spiders 
it is suggested that the proto-spiders may have transferred the sperm to the female by way of a spermatophore which they deposited on the substratum. The pedipalps may initially have assisted in this operation or have merely held open the female genital aperture. It is further suggested that the loss of the spermatophore and retention of the pattern of deposition of the spermatic fluid are to be correlated with the evolution of web-spinning."

Equally numerous authors have studied the morphology of the palpi of male spiders; attempting to interpret the functions of its different components. The most important paper is one by Comstock (I9IO), who described palpi of varied complexity, the simplest being that of the cosmopolitan spider Filistata hibernalis in which the widened palpal tarsus forms a kind of bulb containing the coiled blind duct. The most complex structures are possessed by the Argiopidae. Since I953, Levi has described in detail the male palpal apparatus in various theridiid genera and lately ( I96I) he has studied the evolution of the development of the palpal sclerites in this family. He supposes that in these spiders the simplest palpus is primitive and that the more complex ones indicate a higher degree of evolution.

As to the interpretation of the function of the different parts of the bulbs, authors do not agree with each other; some even believe that these organs have lost their function but still persist. Berland ( 1932) says: "During copula certain parts of the bulb have an important role; the accessory pieces, apophysis of the bulb, the tibia, and the patella, crest of the tarsus, etc., seem to be a completely unnecessary luxury; the attempts made to find a role for each of these parts rest upon the preconceived idea that each organ must have a function."

The different authors who have been interested in this subject do not provide a clear answer to the problem of exactly how the transmission of the sperm from the male palp to the female seminal receptacle is carried out. Equally it is not well established how sperm enters the bulb during sperm induction and how it is expelled during copulation.

\section{Explanation of Plate 21}

Figs. 1-3. Latrodectus geometricus. Fig. 1. Seminal receptacle with male apical element. Fig. 2. Place of separation of apical element. Fig. 3. Complete embolus. -Baez del.

Figs. 4-11. Metepeira sp. Fig. 4. Seminal receptacle with male apical element. Fig. 5. Seminal receptacle with two apical elements. Figs. 6, 7. Location of apical element in the palpus - Argiopid species. Fig. 8. Seminal receptacle with apical element. Fig. 9. Apical element-Metepeira candida. Fig. 10. Seminal receptacle with apical element. Fig. 11. Apical element. -Baez del. 
In the present paper we describe an element of the embolus of the male that in some spiders is retained by the female in her seminal receptacle after copulation. We have found this element in some members of the families Theridiidae and Argiopidae.

The following species of Latrodectus have been examined by us: mactans, curacaviensis, geometricus from Argentina, and mactans (=hasselti) from Australia. In all fertilized females we have found in each seminal receptacle (figs. I, 2O) one or more dark, sclerotized, flagelliform, slightly twisted pieces approximately 200 microns in length; with one end delicately pointed, the structure becoming progressively wider toward its other end. The center of this structure is found to contain a longitudinal transparent tube, circular in section, and opening laterally near the pointed end; at the opposite end the tube seems to be cut.

Adult virgin females, reared individually in the laboratory never contained these elements; nor did females collected in the field and maintained in isolation without ovipositing (fig. 21 ).

On examining unmated males we found the above mentioned element to be the tip of the embolus of the palpus (fig. 3). It is obvious that the transparent tube is the apical portion of what Comstock (I9ro) calls ejaculatory duct, and we shall refer to it here as the apical element.

We wish to emphasize that females that had laid fertile eggs always were found upon dissection to contain the apical element, either within the seminal receptacle, at their entrance, or near them in the ducts. If virgin females of Latrodectus were placed together with males that had not mated and had the emboli complete (as observed under the stereoscopic dissecting microscope), it was found that after mating the apical element was found in the seminal receptricle and was now lacking in the males, having broken off during sperm transmission.

When the apical element is found inside the seminal receptacle, the latter contains a granular seminal mass in which spermatozoa can be found. When the apical element is situated in the canals of the female, this seminal mass is found in the canal. We have never encountered the spermatic mass in females that did not also harbor the male apical element.

The blind end of the palpal tubes of males whose embolus is complete contain the seminal mass; males that lack the apical portion of the embolus (those that have copulated), show only sperm residues in the tubes.

Slide mounts of palpi of unmated males show distinctly the place 
where the embolus will separate (fig. 2); this is particularly conspicuous in Latrodectus geometricus as shown in figures 3 and 22.

It should be emphasized that the phenomenon described is not the accidental breaking-off of the embolus at some place as mentioned by Dahl in 1902 (fide Levi, I959), Smithers (1944), Levi (1959), and lately De Biasi (1962). We have frequently found such different sized parts of the embolus in the female ducts: however we stress that what we describe in the present paper is a well differentiated sclerite normally retained in the seminal receptacle of the female after the male withdraws its palpus. Recently Bhatnagar and Rempel ( 1962) have also observed in a species of Latrodectus a backward directed tooth which gets caught in the female genital organs, making the apical element break off.

The apical element of the embolus of the male of a Metepeira sp. is stouter and more conspicuous than that of Latrodectus; it is strongly sclerotized and its calyx-like shape (figs. 4, 23, 24) calls to mind a Morning Glory flower. Its size is 80 microns, and it has delicate transverse striae. The extreme apex is fish-hook shaped, this hook attaching it to the seminal receptacle; the entrance of the latter is situated directly on the epigynum and a connecting canal is lacking, matching the short male embolus. In some, two apical male elements have been found side by side (fig. 5). Unfertilized adult females have rarely been encountered; in them the potential resting place of the male element can be seen to have a cavity opening agreeing in form and dimensions with those of the apical element, including the place where the hook is to be inserted (fig. 4).

Fertilized females were always found to contain these male elements. The extreme apex of the embolus of unmated males consists of the well-differentiated organ described above, with its ejaculatory duct opening laterally at its distal end. (figs. 6, 7, 24, 25).

In Argiope argentata (Fabr.) the apical element is large and sclerotized, attaining a maximum length of $\mathrm{I} \mathrm{mm}$. Its shape is that of a curved arrow (fig. 26). The female connecting canal is short, sclerotized, funnel-shaped, with a double curve. Fitting into it, the apical element of the male adapts itself to the curvature of the duct. The male element found in the fertilized female shows an irregular zone of rupture from which the ejaculatory duct is separated, distinctly visible.

The ejaculatory duct opens apically. Slide mounts of the epigyna of fertilized females showed in some cases that in addition to correctly placed male elements, another pair was located in the atrium, indicating that copulation has been attempted or accomplished more than 


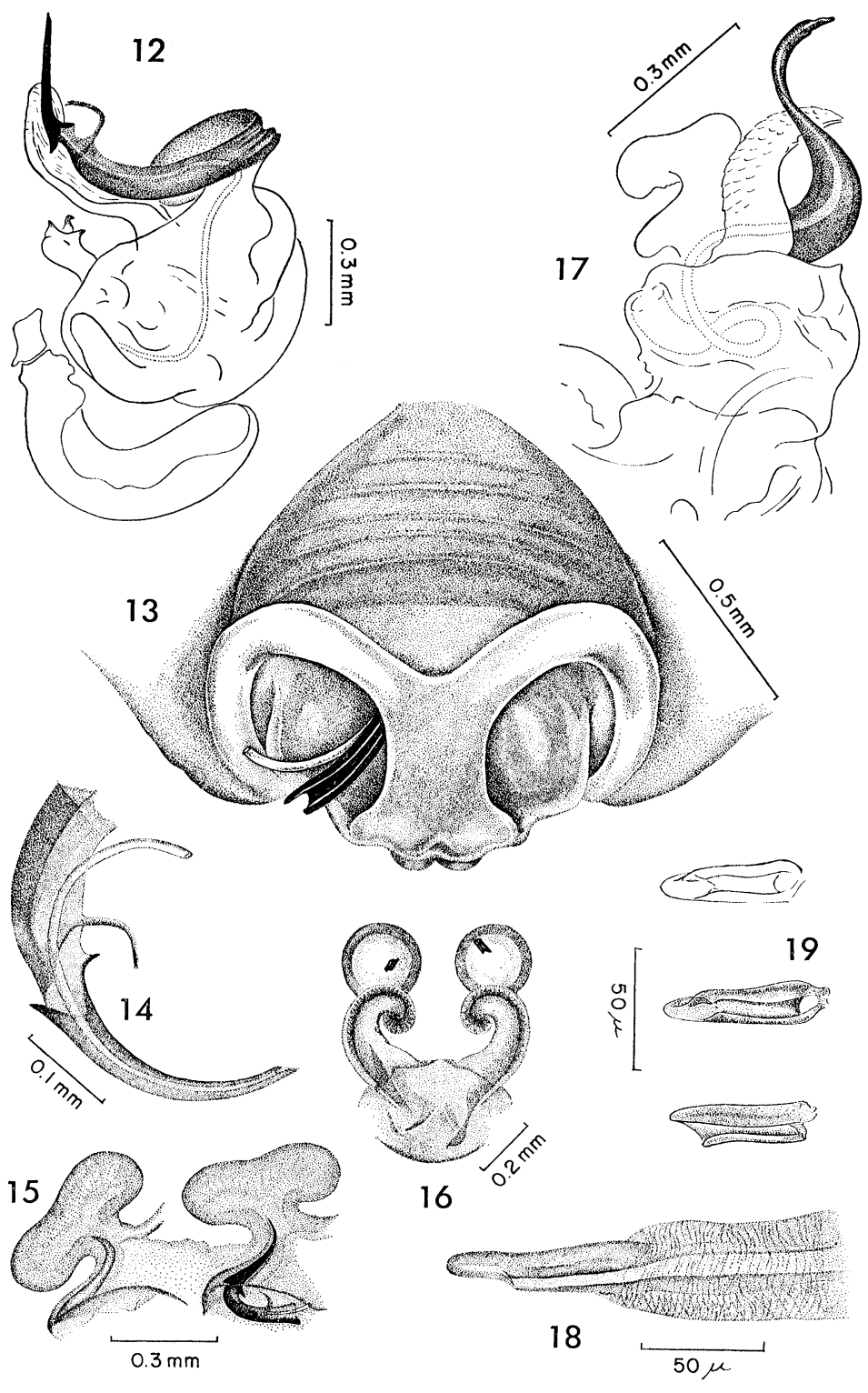

Abalos aNi BAEz - SPIDHRS 
once. In the male, the apical element comprises a large portion of the embolus and no definite place of breaking exists (figs. 12, 27).

The epigynum and the seminal receptacles of other Argiope are similar to those of the foregoing species, and the male element is also very similar (fig. I4), though smaller (less than $0.5 \mathrm{~mm}$ ) (figs. I 5, 28).

The apical element of another undetermined species of Argiopidae is similar to that of Metepeira sp.; its shape is as in figures 8, 9. The element is strongly anchored in the seminal receptacle; more data are not available as it could not be removed without damage, and its position was not favorable for detailed observation. No additional females could be obtained, and the complete male apparatus is not known.

The situation is similar in Metepeira candida (Simon), where the apical element shown in figures $\mathrm{IO}$ and $\mathrm{I} \mathrm{I}$ is anchored in the seminal receptacle.

In the theridiid, Achaearanea tepidariorum (C. L. Koch), the male apical element is found in the interior of the seminal receptacle (figs. 16, 29). The connecting canal of the female is short and sclerotized. The short, stout male embolus (figs. I7, 30) is abruptly narrowed near its conical apex, and at the constriction ends a delicately transversly striate region containing an internal tube of different structure (fig. I 8 ). It is the portion beyond the striate region that remains in the seminal receptacle after mating; it is canaliculate (fig. I9) and its maximum length is 75 microns.

We are not yet able to interpret the function of the apical element, but suggest that in the above mentioned species, transfer of the seminal mass might be by spermatophore, supported by the apical ejement.

In other arachnid orders sperm transmission is by spermatophores. In solpugids, the male emits a sperm mass which he picks up and kneads with his chelicerae, introducing it subsequently into the female genital openings; this sperm-mass is called, by Millot and Vachon ( I 949) and other authors, spermatophore.

In some mites the male transfers a spermatophore to the female

\section{Explanation of Plate 22}

Figs. 12-15. Argiope argentata. Fig. 12. Location of embolus in palpus. Fig. 13. Epigynum with male element in atrium. Fig. 14. Apical element. Fig. 15. Seminal receptacles with apical element.-Baez del.

Figs. 16-19. Achaearanea tepidariorum. Fig. 16. Seminal receptacles containing apical elements. Fig. 17. Embolus of male palpus. Fig. 18. Embolus tip. Fig. 19. Apical element showing several faces. -Baez del. 


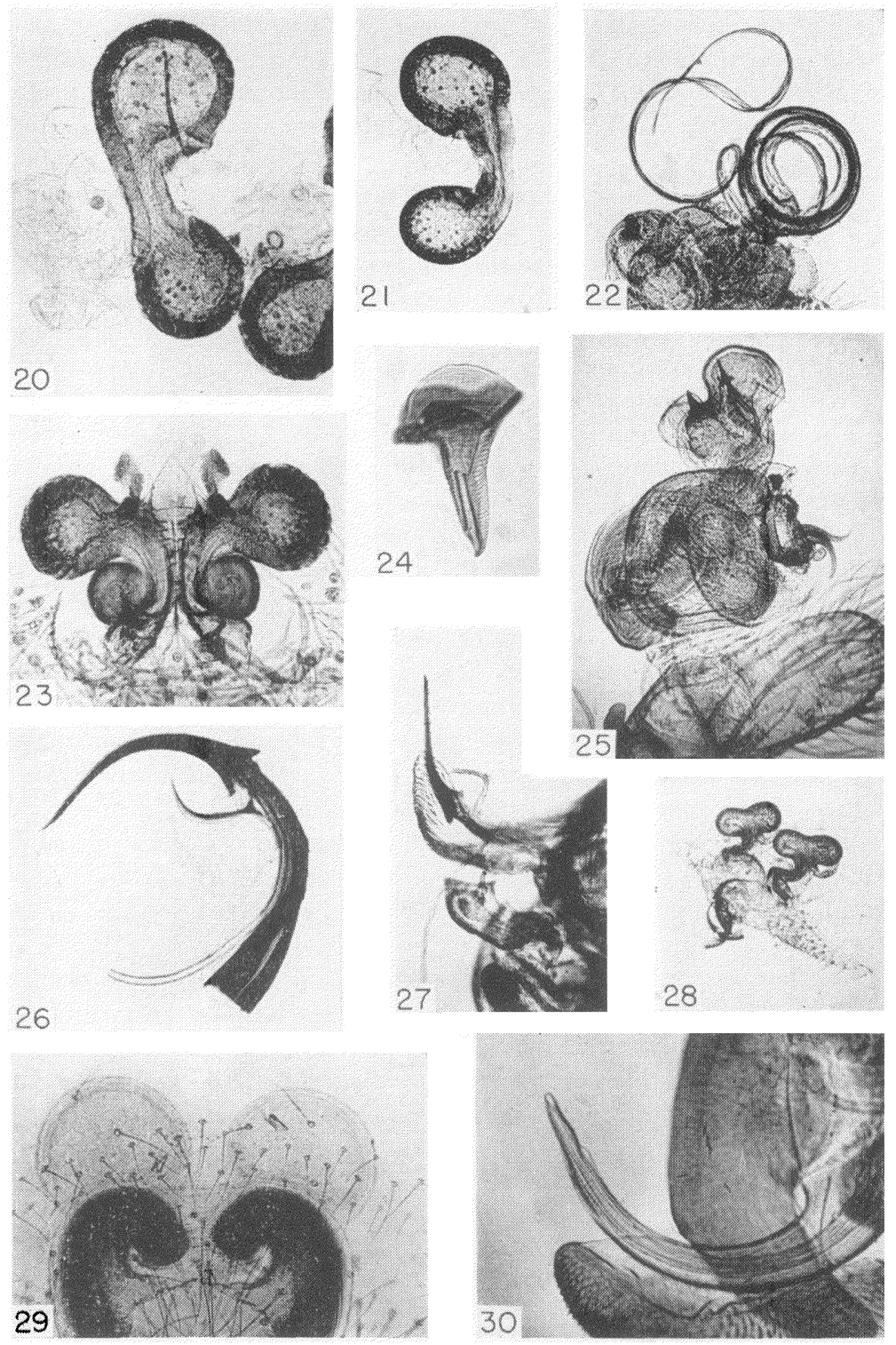

Abatos and Baez - Spiders 
with his chelicera. In pseudoscorpions, the male deposits a spermatophore on the ground, then pulls the female over it (Vachon, 1938). In scorpions, various authors have recently described almost simultaneously the complete mating act, in which a spermatophore is fixed by the male on the substratum (Angerman, 1955; Alexander, 1956, fide Alexander and Ewer, 1957). It has been reported for South American scorpions by Bücherl (1956), Matthiesen (1960) in species of Tityus, and Zolessi (1956) in Bothriurus; the male paraxil apparatus (sclerotized support of the spermatophore) was described for a representative of the family Bothriuridae by Abalos (1955), as an element of the internal anatomy of the male and without taking into account its possible function.

That all arachnids with indirect fertilization employ spermatophores permits us to expect a similar mechanism in spiders. Alexander and Ewer (1957) suggest that a spermatophore could have intervened in the sperm transmission of their hypothetical protoarachnid.

We do not believe that in the theridiids mentioned $(16,29)$ the apical element of the male palpus acts as a simple plug to prevent the loss of seminal liquid from the female reproductive organs. Nor can the flagellar element of Latrodectus act as a plug; it is much too slender to occlude the seminal receptacle or the ducts. However, the apical element of Metepeira species closely fits the entrance of the seminal receptacle, which, lacking a connecting canal, is almost open to the exterior. Here the element might assume the role of a plug.

In Argiope argentata and Argiope sp. the apical element (the posterior portion of which can be seen in fertilized females when the abdomen is inspected from below) is fixed by a granular mass that at the same time obstructs the access to the seminal receptacle (fig. 13). This mass recalls the spermatocleutrum of the scorpions; its presence indicates that fertilization has taken place.

\section{Explanation of Plate 23}

Figs. 20-22. Latrodectus geometricus. Fig. 20. Seminal receptacle with apical element. Fig. 21. Seminal receptacles of virgin female. Fig. 22. Male palpus tip, with embolus.

Figs. 23-25. Metepeira sp. Fig. 23. Seminal receptacle with apical element. Fig. 24. Apical element of embolus extracted from seminal receptacle. 25. Male palpus with apical element of embolus.

Figs. 26-28. Argiope argentata. Fig. 26. Apical element of embolus extracted from seminal receptacle. Fig. 27. Embolus in the male palpus. Fig. 28. Argiope sp., seminal receptacles and atrium with several apical elements.

Figs. 29-30. Achaearanea tepidariorum. Fig. 29. Seminal receptacle with apical elements in its interior. Fig. 30 . Embolus of palpus. 
In additional families of spiders we have found evidence of such an apical element; but, lacking data for both sexes, we have not included these data in the present paper.

The breaking of the apical element of the male palpus is a mutilation that renders the male unable to carry out further matings. If the males of Latrodectus are not killed by the female after mating, they perish in a few days. Authors who have made detailed observations on the mating in different species of Latrodectus, i.e. Herms et al. (1935), D'Amour et al. (1936), Smithers (1944), Baerg (1945) and Shulov (1940), do not mention that copulation was repeated after it had been carried out with both palpi. Herms et. al. (1935) says "In the laboratory the males will readily mate a second time, but the females do not evidence such a tendency." Montgomery says "Promiscuous mating is general, a male impregnating a number of females, and a female receiving a number of males." However no concrete evidence is cited and we believe these two remarks might be the result of mistaken observations.

Of course, not all spiders have been observed to have an apical element. Montgomery (1909) describes in much detail the mating of a pair of salticids, Phidippus purpuratus Keyserling, and observes that the male carries out a new sperm induction every time the mating act is repeated. We ourselves have examined numerous specimens of common domestic salticids without being able to identify an apical element in the male palpus.

This paper is a partial result of research that one of us (Abalos) is carrying out on spiders of the genus Latrodectus, under a grant from the Argentine National Council for Scientific and Technical Research. Our thanks are extended to Dr. and Mrs. Levi for help with determinations and with the preparation of this paper for publication.

\section{REFERENCES}

Abalos, J. W.

1955. Botriurus bertae sp. n. (Bothriuridae, Scorpiones). An. Inst. Med. Regional, Tucumán, $4(2): 231-239$.

Alexander, A. J. and Ewer, D. W.

1957. On the origin of mating behavior in spiders. Amer. Nat., 91: 311317.

BAERg, W. J.

1945. The black widow and the tarantula. Trans. Conn. Acad. Arts Berland, L. Sc., 36: 99-113.

1932. Les arachnides. Paris, 481 pp.

Bhatnagar, R. D. S. ANd J. E. Rempel

1962. The structure, function, and postembryonic development of the male and female copulatory organs of the black widow spider 
Latrodectus curacaviensis (Muller). Canadian Jour. Zool. 40: BüCHERL, W. 465-510.

1956. Escorpioes e escorpionismo no Brasil. V: Observacoes sobre o aparelho reprodutor masculino e o acasalamento de Tityus trivittatus e Tityus bahiensis. Mem. Inst. Butantan, Sao Paulo. 27: 121155.

Comstock, J. H.

1910. The palpi of male spiders. Ann. Ent. Soc. Amer., 3: 161-185.

1940. The spider book. New York.

D'Amour, F. E., F. E. Becker and W. Van Riper

1936. The black widow spider. Quart. Rev. Biol., 11(2) : 123-160.

DE BIASI, P.

1962. Estrutura interna e presenca de segmentos do embolo no epigino de Latrodectus geometricus (Araneidae: Theridiidae). Papeis Avulsos do Dep. Zool., São Paulo, 15 : 327-331.

Herms, W. B., BAILEY, S. F. AND MCIVOR, B.

1935. The black widow spider. Univ. Cal. Agr. Exper. Stat. Bull., Berkeley, 591:1-30.

LEVI, H. W.

1959. The spider genus Latrodectus (Araneae, Theridiidae). Trans. Am. Micr. Soc., $78(1):$ 7-43.

1961. Evolutionary trends in the development of palpal sclerites in the spiders family Theridiidae. J. Morph., 108 (1) : 1-10.

Matthiesen, F. A.

1960. Sobre o acasalamento de Tityus bahiensis (Perty, 1834). Rev. Agr.

MENGE, A. Fac. Filos. Cienc. Letr. Rio Claro, 35 (4) : 341-346.

1843. Über die Lebensweise der Arachniden. Neueste Schriften Naturf. Gesellsch., Danzig, 4.

Millot, J. AND VAchoN, M.

1949. Ordre des solifuges. In Grassé, P. : Traité de Zoologie, Paris, 6 : 482-519.

MONTGOMERY, T. H.

1903. Studies on the habits of spiders, particularly those of the mating period. Proc. Acad. Nat. Sci. Philadelphia, 55: 59-149.

1909. Further studies on the activities of araneads, II. ibid., 61: 548-69.

1910. The significance of the courtship and secondary sexual characters

Shulov, A. of araneads. Am. Nat., 44: 151-177.

1940. On the biology of two Latrodectus spiders in Palestine. Proc. Linn. Soc. London, 152nd Sess.:309-328.

Smithers, R. H. N.

1944. Contributions to our knowledge of the genus Latrodectus (AraVACHON, M. neae) in South Africa. Ann. S. Afr. Mus., 36(3):263-313.

1938. Recherches Anatomiques et biologiques sur la reproduction et le développement des pseudoscorpions. Ann. Sci. Nat. Zool., 11: 1207.

1949. Ordre des Pseudoscorpions. In Grassé, P., Traité de Zoologie, Paris, 6 : 437-481.

Zolessi, L. C. DE.

1956. Observaciones sobre el comportamiento sexual de Bothriurus

bonariensis (Koch). Fac. Agron., Montevideo, 35: 1-10. 

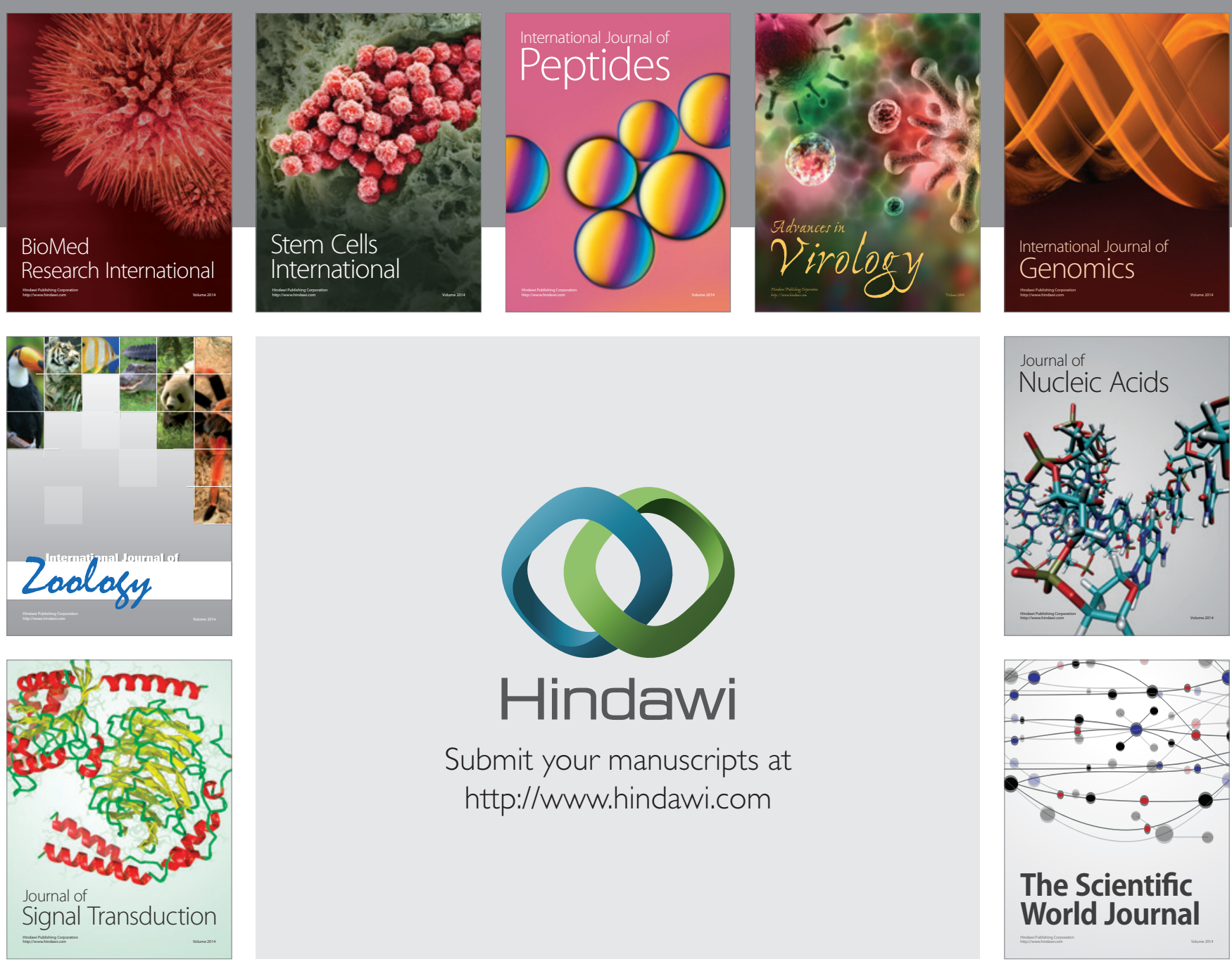

Submit your manuscripts at

http://www.hindawi.com
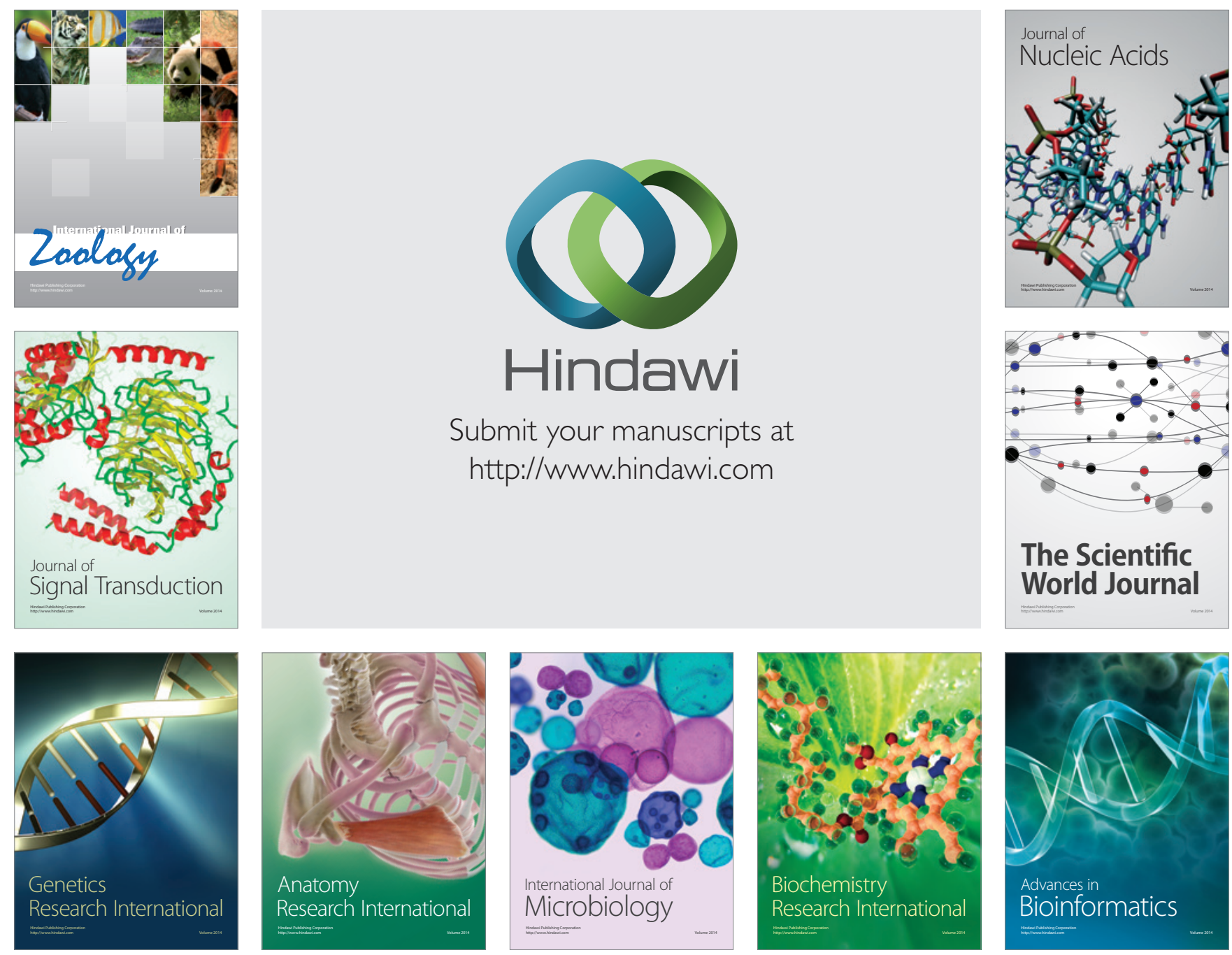

The Scientific World Journal
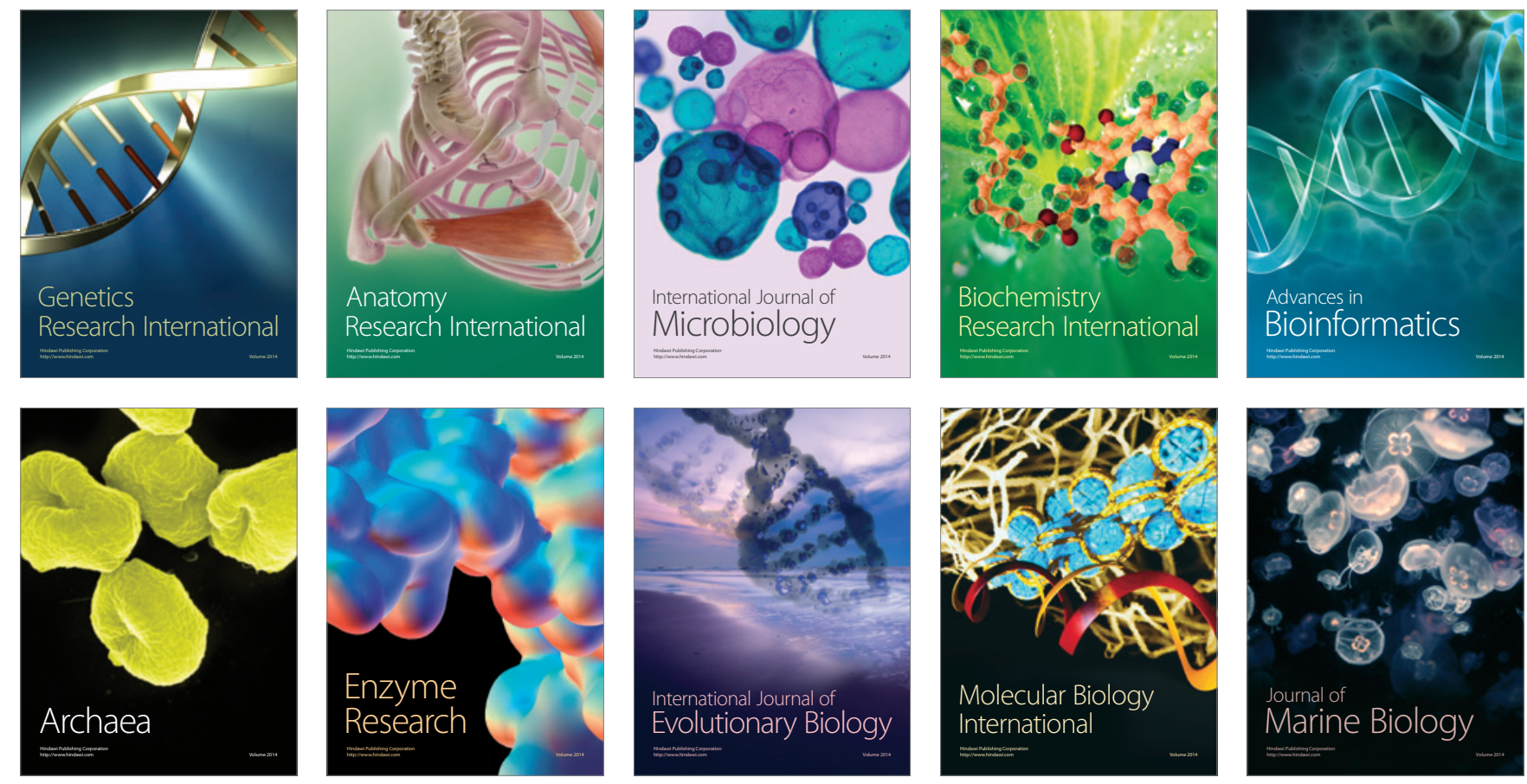